\title{
EL PARTIDO DE LOS COMUNISTAS DE CATALUÑA
}

Los días 9, 10, 11 y 12 de abril de 1982 se celebró en Barcelona el VI Congreso de los Comunistas de Cataluña - Congreso constituyente del Partido de los Comunistas de Cataluña (PCC) - La nueva formación política de ámbito catalán se creó en torno a los treinta y dos firmantes de un documento que provocó su expulsión del PSUC. Nace esta nueva organización en un intento de recuperación de la historia de los comunistas catalanes y en contraposición a las tesis eurocomunistas del PSUC. Para los dirigentes del nuevo partido, la actual dirección del PSUC «ha intentado liquidar el partido, desnaturalizar su historia y engañar a sus bases llevando una política socialdemócrata y abogando públicamente por la desaparición de los comunistas y por su unificación con los socialistas».

El Congreso reunió a 926 delegados en representación de los 7.500 militantes con los que cuenta la nueva formación política catalana. Como resultado del voto secreto de los delegados del Congreso, fue elegido un Comité Central compuesto de 115 miembros que posteriormente elegirían a Pere Ardiaca como presidente y a Joan Ramos como secretario general del Partido.

A continuación ofrezco al lector la Resolución Política del Congreso.

\section{Fernando Ollero Butler}

\section{RESOLUCION POLITICA DEL VI CONGRESO DEL PARTIDO DE LOS COMUNISTAS DE CATALUNA}

Se reunió en Barcelona el VI Congreso de los Comunistas de Cataluña los días 9, 10, 11 y 12 de abril de 1982 y acordó la resolución siguiente:

El VI Congreso se desarrolló en un marco político internacional caracterizado por una nueva ofensiva del imperialismo, encabezado por la administración Reagan de los Estados Unidos, que en un intento de resolver la grave crisis mundial del capitalismo, desarrolla la estrategia de la tensión y del militarismo, poniendo en peligro la paz mundial, ayudando a las dictaduras fascistas en todo el mundo, en unos casos, y en el resto recortando las conquistas democráticas de los pueblos. Detrá de esta política hay el intento de poner en marcha un nuevo modelo de salida capitalista de la crisis, haciendo que las consecuencias de ella recaigan 
sobre los trabajadores y las clases populares exclusivamente. Eso explica la aceleración de los gastos en materia de armamento, el paro estructural en constante aumento tanto en los países desarrollados como en los dependientes.

Los Comunistas de Cataluña llamamos a todos los trabajadores y a todo el pueblo de Cataluña a una solidaridad internacionalista activa con los pueblos que más duramente están sufriendo las consecuencias del ataque imperialista, como son los pueblos de Guatemala, Uruguay, Angola, Turquía, el pueblo palestino y saharaui y concretamente con el pueblo de El Salvador y su lucha heroica encabezada por el FDR-Farabundo Martí de Liberación Nacional. Llamamos a dar ayuda incondicional a los pueblos de Cuba socialista y de Nicaragua revolucionaria, amenazados hoy por la arrogancia imperialista.

En estrecha relación con esta lucha antiimperialista los Comunistas de Cataluña llamamos a iniciar una amplia movilización por la paz, la distensión, el desarme, ayudamos a la iniciativa de las Naciones Unidas de desarrollar una campaña de lucha por la paz, el próximo mes de junio y nos reafirmamos en nuestro rechazo a la entrada de España en la OTAN y en la exigencia del desmantelamiento de todo tipo de bases americanas en España.

\section{La crisis económica y social}

Nuestro Congreso se ha dado en un contexto de grave crisis económica y social que se constata, en nuestro país, en una alarmante situación de paro. Tanto el reformismo, como la derecha encabezada por UCD, con el apoyo de CiU, pretende una solución pactista con condiciones realmente peligrosas para la clase obrera. Los Comunistas de Cataluña ya denunciamos en su día la firma del ANE porque se configuraba como un pacto social que no frenaba el crecimiento del paro y que, en cambio ataca el poder adquisitivo de los trabajadores desmovilizándolos. Delante de este pactismo claudicante los comunistas proponemos el movimiento sindical, el descolgamiento del ANE, oponiendo una línea de resistencia a la crisis, que dé una respuesta en un plano económico, social, sindical e institucional a la política de la oligarquía y haga frente al proceso de división y corporatización que los efectos de la crisis introducen en la clase obrera y en los sectores populares. Los Comunistas de Cataluña rechazan el pacto social por cuatro años que tanto la patronal como algunos sectores sindicales pretenden firmar.

Los Comunistas de Cataluña dan soporte al sindicalismo de clase, de masas, democrático, independiente, nacional, internacionalista y unitario de CC.OO., impulsando, hoy más que nunca, el carácter de sindicato sociopolítico que CC. OO. ha mantenido siempre. Llamamos a todos los comunistas, como a todos los trabajadores, a ayudar a CC. OO. de cara a conseguir que en las próximas elecciones sindicales triunfen las candidaturas de CC. OO., manteniendo este sindicato como el sindicato mayoritario y hegemónico dentro de la clase obrera.

Este soporte a la lucha de CC. OO. y de la clase trabajadora en contra del paro y los efectos de la crisis, tiene que hacerse patente en una participación masiva de los comunistas, de sus amigos y simpatizantes, de toda la clase obrera, en las manifestaciones y otras acciones alrededor del próximo 1 de mayo donde se demuestre, junto con la lucha por los problemas específicos de la clase obrera de Cataluña, su solidaridad internacionalista con los obreros de los pueblos de todo el mundo.

Frente a las actuaciones de los sectores fascistas y golpistas que continúan manteniendo contra las conquistas democráticas de los pueblos de España, y que tuvieron su momento álgido en los hechos del 23 de febrero, el VI Congreso muestra su total rechazo a la instrumentalización que los medios fascistas quieren 
hacer del juicio que estos días se celebra en Madrid, y que se está convirtiendo en un juicio en contra de las libertades y de la democracia. Estos hechos y los constantes recortes de las libertades elementales de expresión, reunión, manifestación, etc., demuestran la necesidad de una depuración de los elementos fascistas y de los nostálgicos del franquismo que aún están presentes en los aparatos del Estado y en todos los niveles de la Administración. El VI Congreso denuncia las actuaciones típicamente franquistas de las autoridades gubernativas con hechos como la marcha de Lemmerz y Estampaciones Sabadell, en las manifestaciones contra los juicios a las abortistas del País Vasco, que las detenciones en Tarragona a las manifestaciones por la paz y contra el paro, la represión de los mineros de Badajoz y de Huelva. El VI Congreso hace suya la petición de dimisión inmediata de los gobernadores civiles y autoridades gubernativas en esta represión que se está desencadenando en todo el Estado contra la clase obrera y el pueblo.

EI VI Congreso llama a todo el pueblo de Cataluña a la movilización contra los cortes que está teniendo el derecho de autogobierno de Cataluña como consecuencia de los acuerdos antiautonómicos entre la UCD y el PSOE. La instrumentalización que se quiere hacer del Tribunal Constitucional, e iniciativas, claramente, como la LOAPA, ponen en peligro los derechos nacionales de Cataluña. Con el espíritu solidario con todas las naciones y pueblos del Estado español y en defensa de los derechos nacionales de Cataluña, los comunistas luchamos y lucharemos por el pleno desarrollo del derecho de autodeterminación de Cataluña en la perspectiva de un Estado republicano y federal. Esta vía, opuesta a la alternativa del capitalismo conservador de $\mathrm{CiU}$ y de la derecha catalana, es la más consecuente para avanzar hacia la reconstrucción nacional popular en Cataluña. La hegemonía de la clase obrera en esta lucha es la única garantía de su desarrollo consecuente y de la plena solidaridad de todos los pueblos que constituyen el Estado español.

\section{Degradación de la enseñanza}

El VI Congreso de los Comunistas de Cataluña denuncia la creciente degradación de la calidad de la enseñanza, propiciada por el gobierno Calvo Sotelo y, en Cataluña, por Convergència $i$ Unió, con medidas como el aumento del número de alumnos por aula, disminución de asignaturas, de profesorado. Todo esto está en la estrategia de la derecha y del gran capital de reducir, cada día más, las prestaciones sociales a la población. Los comunistas llamamos a los enseñantes, a los padres de alumnos, a los alumnos y a los trabajadores en general, a la lucha por la escolarización en condiciones, que garantice una escuela de calidad, en el camino hacia la escuela pública.

Por otro lado, el VI Congreso de los Comunistas de Cataluña denuncia el proyecto de la LAU como un proyecto regresivo, hecho en función de los intereses de la derecha, a través de un consenso, que criticamos, entre la UCD y los socialistas. Los Comunistas de Cataluña llaman a todos los sectores de la Universidad y los trabajadores, en general, a relanzar la lucha por una Universidad auténticamente democrática, pública, autónoma, científica y catalana.

Nuestro Congreso urge a todos los comunistas, a todos los trabajadores, a un trabajo activo en el movimiento de masas, movimiento juvenil, sindical (CC. OO., STATC, ATAC), movimientos ecologistas, Unió de Pagesos, Asociaciones de Vecinos, Movimiento Feminista, y a todos los movimientos populares que tienen que ser instrumentos fundamentales de participación del pueblo en nuestro proyecto de transformación revolucionaria de la sociedad. 
E1 VI Congreso de los Comunistas de Cataluña demuestra su preocupación por los problemas graves que sufre el campo catalán y da plena ayuda a las justas reivindicaciones de los campesinos y trabajadores del campo.

\section{Rechazo al ingreso al Mercado Común}

El VI Congreso de los Comunistas de Cataluña rechaza los métodos que se siguen el proceso de integración de España en el Mercado Común, política llevada a cabo por el gobierno Calvo Sotelo con la ayuda de $\mathrm{CiU}$ y que obedece a los intereses del capital multinacional y a su concepción de la división internacional del trabajo, en contra de los intereses económicos de la clase obrera y de las capas populares, de las capas medias, de la pequeña y media burguesía y de los sectores agrícolas. En las actuales circunstancias es necesario que nuestro partido analice a fondo las consecuencias económicas, políticas y sociales de la integración, y es necesario que el debate en el seno del partido tenga una dimensión más amplia que permita hacer de este tema una discusión popular y abierta.

El VI Congreso de los Comunistas de Cataluña es el resultado de un amplio movimiento crítico y de base de los militantes comunistas que ha decidido decir basta a la política claudicante, reformista y elitista que representa el eurocomunismo, que ha decidido dotar a los trabajadores y al pueblo de Cataluña del Partido Comunista que necesitamos. El Partido de los Comunistas de Cataluña se considera continuador del PSUC fundado el 23 de julio de 1936 y hace suya su tradición revolucionaria y reivindica la totalidad de su patrimonio histórico, de acuerdo con la legítima política expresada en el $\mathrm{V}$ Congreso.

Como Comunistas de Cataluña somos un partido de clase y nacional y afirmamos que la clase más nacional es la clase obrera, la única que expresa desde sus propias condiciones los intereses objetivos y colectivos de Cataluña como nacionalidad.

El Partido de los Comunistas de Cataluña aspira a ser la organización de vanguardia del movimiento progresista y revolucionario del pueblo de Cataluña. Un partido que afronta la gran tarea política e ideológica de estímulo de la conciencia y de la cohesión de la clase obrera que, ya hoy, tiene una estrecha relación con los sectores populares y que corea su espíritu antifascista, difundiendo las ideas del socialismo y del comunismo.

\section{Principios del marxismo-leninismo}

El PCC es un partido que se organiza, que interpreta la realidad y aspira a transformarla haciendo suyos los principios del marxismo-leninismo. Un partido democrático donde todos los militantes participen en la elaboración de la línea política y en la elección de los organismos de dirección, que busca la síntesis permanente entre el debate y la acción, la teoría y la práctica mediante el centralismo democrático.

El PCC es un partido internacionalista que lucha por el socialismo y el comunismo en las condiciones específicas de Cataluña y de España y solidario, desde una concepción universal, con todos los partidos y pueblos que luchan por la paz y el progreso, que combaten el imperialismo y avanzan en las diversas condiciones sociales e históricas por el camino de su emancipación.

El Partido de los Comunistas de Cataluña está dispuesto a establecer relaciones políticas de fraternidad, con los comunistas del conjunto del Estado es- 
pañol que, organizados oportunamente, expresen sus coincidencias, mantengan los mismos principios, la misma política general y los mismos métodos de organización.

El Partido de los Comunistas de Cataluña quiere mantener relaciones de fraternidad, de manera soberana, con todos los partidos comunistas del mundo, sobre la base del internacionalismo proletario, en la vía de ampliar su cooperación, coordinación y actuación conjunta.

El VI Congreso del Partido de los Comunistas de Cataluña llama a todos los trabajadores, conscientes de su explotación, a todos los revolucionarios y a todos los comunistas a ingresar en las filas de nuestro partido, a trabajar y a luchar conjuntamente con nosotros por la transformación de la sociedad, en lucha por el socialismo y el comunismo.

Barcelona, 12 de abril de 1982. 